\title{
Malaria Clusters among Illegal Chinese Immigrants to Europe through Africa
}

\section{Zeno Bisoffi, ${ }^{*}$ Alberto Matteelli, $\dagger$ Donatella Aquilini,‡ Giovanni Guaraldi,§ Giacomo Magnani,, Giovanna Orlando,\# Giovanni Gaiera,** Tomas Jelinek, †† and Ron H. Behrensł‡}

Between November 2002 and March 2003, 17 cases of malaria (1 fatal) were observed in illegal Chinese immigrants who traveled to Italy through Africa. A further cluster of 12 was reported in August, 2002. Several immigrants traveled by air, making the risk of introducing sudden acute respiratory syndrome a possibility should such illegal immigrations continue.

From November 2002 to March 2003, 17 cases of $F$ malaria were noted among illegal Chinese immigrants in seven hospitals across central and northern Italy (15 cases of Plasmodium falciparum, 1 case of P. malariae, and 1 mixed infection of P. falciparum and P. malariae). One patient died. Until recently, imported malaria in this group of illegal immigrants from China was not detected by malaria surveillance institutions within Europe (1). Although malaria is still endemic in parts of China, transmission in these regions is low-level (2); the predominant species is $P$. vivax. P. falciparum transmission is confined to provinces bordering Laos and Viet Nam. None of the patients reported coming from those areas. Investigating the cluster proved difficult because of language problems and reticence to provide detailed information of travel, since the patients were illegal immigrants (Table). The fatal case occurred in a general hospital in northern Italy. The 20-year-old woman (case 7) was admitted with a high fever, severe hemolytic anemia (hemoglobin $4.4 \mathrm{~g} / \mathrm{dL}$ ), and metabolic acidosis. After 48 hours, because of hypotension, seizures, and subsequent coma, she was transferred to the intensive-care unit of a referral hospital

*Ospedale S. Cuore, Negrar, Verona, Italy; †Università di Brescia, Brescia, Italy; ‡Ospedale di Prato, Prato, Italy; §Università di Modena, Modena, Italy; đOspedale di Reggio Emilia, Reggio Emilia, Italy; \#Ospedale Sacco, Milano, Italy; ${ }^{* *}$ Ospedale S. Raffaele, Milano, Italy; ††Institute of Tropical Medicine, Berlin, Germany; and \$‡London School of Hygiene and Tropical Medicine, London, United Kingdom for infectious diseases. The blood film showed a 70\% parasitemia with $P$. falciparum. The patient died 96 hours after admission, despite aggressive drug therapy and plasmapheresis.

\section{Discussion}

Before 2000, no cases of $P$. falciparum had occurred in Chinese immigrants living in northern and central Italy, despite a large immigrant population. An initial cluster of 22 cases was described during summer 2000 in the Lombardy Region (3). A cluster of six cases was detected in Tuscany during the same period (4). In both outbreaks, the researchers described high rates of severe disease. All patients were exposed to malaria during a prolonged journey to Europe (3-9 months) through a number of Asian and African countries.

From 2000 to 2002, a total of 10 sporadic cases were reported to the Italian Ministry of Health in 2001 (L. Vellucci, Directorate for Prevention, Ministry of Health, Italy, pers. comm.). The 2003 cluster prompted us to examine hospital records from August 2002, where we identified an additional, previously undetected, cluster of 12 malaria cases in four of our study hospitals (data not included in the table). The Ministry of Health had 26 confirmed P. falciparum cases during 2002 (L. Vellucci, pers. comm.), suggesting an ongoing (and possibly increasing) influx of Chinese laborers. Some differences exist between the later cluster and the 2000 cluster. In the 2003 cluster, the proportion of severe cases was lower than in the previous reports, with a patient with a fatal case first admitted to a general hospital where diagnosis of malaria was not considered; in the others, awareness of the possibility of malaria had been raised by the earlier cluster $(3,4)$ and led to prompt diagnosis and treatment, with favorable outcome. A single African country, Côte d'Ivoire, was the transit country for most of the patients. In previous cases, a number of other African countries were used for transit. Visa processing for entry to Europe was arranged by the courier organization in Côte d'Ivoire. The clustering of cases suggests that the illegal immigrants arrive in Europe in groups. Although Italy was the final destination, at least some immigrants entered through France, which also has had reports of $P$. falciparum cases in Chinese immigrants (F. Legros, Centre National de Référence de l'Epidémiologie du Paludisme, France, pers. comm.). As malaria is probably underreported in Europe, additional cases may well have occurred.

Use of clandestine travel by air to emigrate from China, where sudden acute respiratory syndrome (SARS) is present, poses a threat for the African countries, where the introduction of SARS virus could have devastating consequences on their health systems with a potential overlap with the HIV epidemic. Other diseases could be spread or 
DISPATCHES

Table. Characteristics of 17 cases of malaria in illegal Chinese immigrants, Italy

\begin{tabular}{|c|c|c|c|c|c|c|c|c|}
\hline Case & Sex, age ${ }^{a}$ & $\begin{array}{l}\text { Date first } \\
\text { seen by } \\
\text { physician }\end{array}$ & Country of transit & $\begin{array}{l}\text { Time spent in } \\
\text { country of } \\
\text { transit }\end{array}$ & $\begin{array}{l}\text { Mode of } \\
\text { travel }\end{array}$ & $\begin{array}{l}\text { Mode of } \\
\text { travel to } \\
\text { Europe }\end{array}$ & Plasmodium species & Clinical outcome \\
\hline 1 & $\mathrm{M}, 21$ & $11 / 05 / 02$ & Côte d'Ivoire & $8 \mathrm{mo}$ & Air & Air & P. falciparum & Recovered \\
\hline 2 & M, 24 & $11 / 11 / 02$ & "Africa" & $3 \mathrm{mo}$ & Unknown & Air & P. falciparum & Recovered \\
\hline 3 & $\mathrm{~F}, 20$ & $11 / 12 / 02$ & Côte d'Ivoire & $22 \mathrm{~d}$ & Road/sea & Air & P. falciparum & Recovered \\
\hline 4 & M, 22 & $11 / 15 / 02$ & Côte d'Ivoire & $1 \mathrm{mo}$ & Air & Air & P. falciparum & Recovered \\
\hline 5 & M, 24 & $11 / 16 / 02$ & Côte d'Ivoire & $14 \mathrm{~d}$ & Road/sea & Air & P. falciparum & Recovered \\
\hline 6 & M, 28 & 01/09/03 & Côte d'Ivoire & $2 \mathrm{mo}$ & Unknown & Air & P. falciparum & Recovered \\
\hline 7 & $\mathrm{~F}, 20$ & $01 / 13 / 03$ & Côte d'Ivoire & Few days & Unknown & Air & P. falciparum & Died \\
\hline 8 & M, 21 & 02/01/03 & Côte d'Ivoire & Unknown & Unknown & Air & P. falciparum & Recovered \\
\hline 9 & $\mathrm{~F}, 32$ & $02 / 02 / 03$ & Congo & Unknown & Unknown & Air & P. falciparum & Recovered \\
\hline 10 & M, 22 & $02 / 03 / 03$ & Côte d'Ivoire & $6 \mathrm{mo}$ & Air & Air & P. falciparum & Recovered \\
\hline 11 & M, 19 & $02 / 08 / 03$ & Côte d'Ivoire & Unknown & Unknown & Air & P. falciparum & Recovered \\
\hline 12 & M, 34 & $02 / 13 / 03$ & Congo & $2 \mathrm{mo}$ & Road/sea & Air & $\begin{array}{c}P . \text { falciparum and } P \text {. } \\
\text { malariae }\end{array}$ & Recovered \\
\hline 13 & $\mathrm{~F}, 24$ & $02 / 13 / 03$ & Côte d'Ivoire & $50 \mathrm{~d}$ & Air & Air & P. falciparum & Recovered \\
\hline 14 & $\mathrm{M}, 40$ & $02 / 22 / 03$ & Côte d'Ivoire & Unknown & Road/sea & Air & P. falciparum & Recovered \\
\hline 15 & M, 22 & $02 / 24 / 03$ & Côte d'Ivoire & $2 \mathrm{mo}$ & Road/sea & Air & P. falciparum & Recovered \\
\hline 16 & M, 28 & 03/01/03 & “Africa” & Unknown & Unknown & Air & P. falciparum & Recovered \\
\hline 17 & M, 23 & $03 / 15 / 03$ & Côte d'Ivoire & $50 \mathrm{~d}$ & Road/sea & Air & P. malariae & Recovered \\
\hline
\end{tabular}

acquired by the immigrants in the countries of transit. While curtailing the huge, illegal immigrant system to Europe is difficult, we cannot overemphasize the need for a sound surveillance on imported infectious diseases in this continent.

Both clusters of malaria were detected early through Salute Internazionale Regione Lombardia (SIRL), a network on imported diseases of the Lombardy Region, in conjunction with the European Network on Imported Infectious Disease Surveillance (TropNetEurop). Any physician in Europe who sees a Chinese patient with a history of recent travel and a high fever should exclude malaria, besides considering the possible diagnosis of SARS. Respiratory symptoms are also frequent in uncomplicated malaria $(5,6)$, and acute respiratory distress syndrome has long been recognized as one of the main features of severe malaria $(7,8)$.

\section{Acknowledgments}

We are grateful to Loredana Vellucci, Stefania D'Amato, and Fabrice Legros for providing information on malaria in Chinese immigrants in Italy and France, respectively.

Dr. Bisoffi is the head of the Center for Tropical Diseases at the Sacro Cuore Hospital of Negrar, Verona, Italy, a referral center for imported diseases. His main research interests concern the surveillance and diagnosis of imported tropical and infectious diseases and the clinical decision-making in tropical medicine.
$\mathrm{He}$ is the secretary general of the Italian Society of Tropical Medicine and teaches in several Italian and European institutes.

\section{References}

1. Jelinek T, Schulte C, Behrens R, Grobusch MP, Coulaud JP, Bisoffi $\mathrm{Z}$, et al. Imported Falciparum malaria in Europe: sentinel surveillance data from the European network on surveillance of imported infectious diseases. Clin Infect Dis 2002;34:572-6.

2. Shen J, Zhang S, Xu B, Cheng F, Pei S, Ye J, et al. Surveillance for low-level malaria. Trans R Soc Trop Med Hyg 1998;92:3-6.

3. Matteelli A, Volonterio A, Gulletta M, Galimberti L, Marocco S, Gaiera G, et al. Malaria in illegal Chinese immigrants, Italy. Emerg Infect Dis 2001;7:1055-8.

4. Aquilini D, Liang LI, Paladini A. New slaves and malaria. J Travel Med 2003;10:46-7.

5. Anstey NM, Jacups SP, Cain T, Pearson T, Ziesing PJ, Fisher DA, et al. Pulmonary manifestations of uncomplicated falciparum and vivax malaria: cough, small airways obstruction, impaired gas transfer, and increased pulmonary phagocytic activity. $J$ Infect Dis 2002;185:1326-34.

6. Gozal D. The incidence of pulmonary manifestations during Plasmodium falciparum malaria in non immune subjects. Trop Med Parasitol 1992;43:6-8.

7. Brooks MH, Kiel FW, Sheehy TW, Barry KG. Acute pulmonary edema in falciparum malaria. N Engl J Med 1968;279:732-7.

8. Severe falciparum malaria. World Health Organization, Communicable Diseases Cluster. Trans R Soc Trop Med Hyg 2000;94(Suppl 1):S190.

Address for correspondence: Zeno Bisoffi, Centro per le Malattie Tropicali, Ospedale Sacro Cuore, 37024 Negrar-Verona, Italy; fax: 390456013694; email: zeno.bisoffi@sacrocuore.it 